\title{
16p subtelomeric duplication: a clinically recognizable syndrome
}

\author{
Maria Cristina Digilio*,1, Laura Bernardini ${ }^{2}$, Anna Capalbo ${ }^{2}$, Rossella Capolino ${ }^{1}$, \\ Maria Giulia Gagliardi ${ }^{1}$, Bruno Marino ${ }^{3}$, Antonio Novelli ${ }^{2}$ and Bruno Dallapiccola ${ }^{2}$ \\ ${ }^{1}$ Medical Genetics and Pediatric Cardiology, Bambino Gesù Hospital, Rome, Italy; ${ }^{2}$ Department of Experimental
Medicine, Sapienza University and CSS-Mendel Institute, Rome, Italy; ${ }^{3}$ Pediatric Department, Pediatric Cardiology
Unit, Sapienza University, Rome, Italy
}

We report on two patients with duplication of the subterminal region of chromosome 16p (dup16p) recognized by fluorescent in situ hybridization (FISH) telomere analysis, presenting with closely overlapping facial features and neurological impairment. Distinct facial anomalies included high forehead, sparse eyebrows, blepharophimosis, short nose, everted upper lip, high-arched palate, wide-spaced teeth, and cupped anteverted ears. Susceptibility to vascular anomalies, in particular pulmonary hypertension and portal cavernoma, was found in one patient. Subtelomeric analysis by FISH demonstrated a de novo duplication of the subtelomeric region of chromosome $16 \mathrm{p}$ and a deletion of the subtelomeric region of chromosome $4 q$ in case 1 , and duplication of the subtelomeric region of $16 p$ and a deletion of the subtelomeric region of $21 \mathrm{q}$, resulting from malsegregation of a balanced maternal traslocation $t$ (16pter;21qter) in case 2 . The extension of duplicated regions measured by array-comparative genome hybridization was about $12 \mathrm{Mb}$ on $16 \mathrm{p} 13.3 \mathrm{p} 13.13$ in case 1 , and about $8.5 \mathrm{Mb}$ on 16p13.3p13.2 in case 2 . In conclusion, we reported a clinically recognizable disorder in two patients with dup16p. Pulmonary hypertension, vascular ring, and manifestations of vascular disruption, as terminal hypoplasia of hands and aplasia cutis, have been previously described in association with dup16p. Thus, susceptibility to pulmonary vascular disease and other vascular anomalies can be a feature of dup16p, suggesting that this subtelomeric region in some respect could be related to vascular anomalies.

European Journal of Human Genetics (2009) 17, 1135-1140; doi:10.1038/ejhg.2009.14; published online 18 March 2009

Keywords: duplication chromosome 16p; comparative genomic hybridization; pulmonary hypertension

\section{Introduction}

Partial trisomy $16 \mathrm{p}$ is a rare chromosome imbalance characterized by mental retardation, prenatal and postnatal growth deficiency, facial anomalies, cleft palate, congenital heart defect, and urogenital anomalies. ${ }^{1-9}$ Only a few patients have been reported, the majority of which manifest chromosome duplications resolved by standard cytogenetic techniques. Previous studies have

${ }^{*}$ Correspondence: $\operatorname{Dr}$ MC Digilio, Medical Genetics, Bambino Gesù Hospital, Piazza S. Onofrio 4, 00165, Rome, Italy.

Tel: + 39066859 2227; Fax: + 39066859 2004; E-mail: digilio@opbg.net Received 1 September 2008; revised 6 January 2009; accepted 15 January 2009; published online 18 March 2009 established that the phenotypic severity could not be correlated with the size of the duplicated segment, and region $16 \mathrm{p} 13.1-\mathrm{p} 13.3$ is 'critical' in determining this disorder. Telomere analysis has also identified cryptic duplications of the subterminal region of chromosome 16p (dup16p), which was considered less rare than originally thought. $8,10,11$

We report on two patients with dup16p recognized by fluorescent in situ hybridization (FISH) telomere analysis, presenting with closely overlapping facial features, neurological impairment, and urinary malformations. Susceptibility to vascular anomalies, in particular pulmonary hypertension and portal cavernoma, was found in one case. 


\section{Subjects \\ Patients}

Patient 1 This patient, a female, was the first child of healthy nonconsanguineous parents. At birth, the mother was 28-year old and the father 23. Family history was unremarkable. The baby was born by vaginal delivery at the 35th week of an uneventful gestation. Birth weight was $2500 \mathrm{~g}$, length $48 \mathrm{~cm}$, and head circumference $33.5 \mathrm{~cm}$. Apgar scores were 8 and 9 at $1^{\prime}$ and $5^{\prime}$, respectively. The patient was first seen by us at 6 months. Weight was $5300 \mathrm{~g}$ ( $<3$ rd centile), length $58.5 \mathrm{~cm}$ ( $<3$ rd centile), and head circumference $38 \mathrm{~cm}$ ( $<3 \mathrm{rd}$ centile). Clinical evaluation disclosed microcephaly, bilateral blepharophimosis, everted upper lip, anteverted ears, and mild fingers' camptodactyly. The baby was hypotonic and developmental milestones were delayed. Feeding difficulties required nasogastric tubes in the first 4 months of life. The patient underwent surgical correction of bilateral inguinal hernia at 3 months.

Portal hypertension was diagnosed in the first month of postnatal life. Magnetic resonance angiography demonstrated a portal vein cavernoma with esophageal varices. Liver and spleen were enlarged. A corrective meso-portal bypass surgery was performed.

Two-dimensional color Doppler echocardiography showed patent ductus arteriosus and a small atrial septal defect ostium secundum type. Patent ductus arteriosus was operated at 2 months. A routine color Doppler echocardiography at 2 years disclosed severe pulmonary hypertension with dilatation of the right heart chambers and the pulmonary artery. The pulmonary hypertension was idiopathic and not related to congenital heart defects. Cardiac catheterization showed systemic level pulmonary artery pressure, elevated pulmonary vascular resistance, and no response to administration of oxygen and nitric oxide.

Cerebral MRI demonstrated corpus callosum hypoplasia. EEG and brain stem audiometry were normal. Ophthalmological examination revealed bilateral mild optic nerve hypoplasia. Renal ultrasonography showed an ectopic left kidney.

At 2.4 years, weight was $8.350 \mathrm{~kg}$ ( $<3$ rd centile), height $68 \mathrm{~cm}$ ( $<3 \mathrm{rd}$ centile), and head circumference $44.5 \mathrm{~cm}$ $(<3$ rd centile). Clinical characteristics included blond fine hairs, sparse eyebrows, bilateral palpebral ptosis with narrow palpebral fissures, asymmetric nares, short philtrum, open mouth with everted upper lip, narrow palate, dental malposition with diastema, and cupped anteverted ears (Figure 1a and b). Moderate mental retardation was detected by neuropsychological testing, and language was absent.

Patient 2 This patient was a 3.7-year-old female. At birth, the mother was 28-year old and the father 30. Parents were nonconsanguineous, and family history was unremarkable.
The baby had a healthy dizygotic co-twin. The proband was born by vaginal delivery at the 39th week of an uneventful gestation. Birth weight was $2430 \mathrm{~g}$, length $47 \mathrm{~cm}$, and head circumference $34 \mathrm{~cm}$. Apgar scores were 6 and 8 at $1^{\prime}$ and $5^{\prime}$, respectively. The patient was evaluated by us at 3.7 years. Weight was $12 \mathrm{Kg}$ ( $<3$ rd centile), height $101 \mathrm{~cm}$ (75th-90th centile), and head circumference $50 \mathrm{~cm}$ (50th centile). On clinical evaluation, the patient disclosed blond thin hair (blonder that the familial background), high frontal hairline, narrow palpebral fissures with bilateral ptosis, short philtrum, everted upper lip, high arched palate, dental caries, micrognathia, cupped anteverted ears (Figure 1c and d), and hypoplastic distal phalanges with clubbed nails. A right congenital hip dysplasia was operated at 6 months. Developmental milestones were moderately retarded. The baby was sitting at 12 months, and walked alone at 2 years. Language was absent. She was hyperactive and showed self-injurious behavior. Feeding difficulties were recorded in the first 2 years of life (Figure 2).

Cerebral MRI, ophthalmologic evaluation, brainstem audiometry, and two-dimensional color Doppler echocardiography were normal. Renal ultrasonography and cystourethrography disclosed grade IV left vesicoureteral reflux with unilateral hydronephrosis and hypoplastic kidney on the left.

\section{Results}

Chromosome analyses were carried out on peripheral lymphocytes using standard techniques. Subtelomeric regions were analyzed using ToTelVysion kit (Vysis Inc., Downers Grove, IL, USA), according to manufacturer's suggestions. To characterize the extension of the subtelomeric imbalances, array-comparative genome hybridization (CGH) analysis was performed using an oligonucleotide microarray with a genomic resolution of about $100 \mathrm{~kb}$ (44K; Agilent Technologies, Waldbronn, Germany), according to Bernardini et al. ${ }^{12}$ Slides were imaged with Feature Extraction software (v8.5) and chromosomal profiles were obtained using the CGH Analytics software (v3.4.40; Agilent Technologies).

In patient 1 , standard chromosome analysis disclosed a normal 46,XX karyotype. Subtelomeric analysis by FISH demonstrated a de novo duplication of the subtelomeric region of chromosome $16 \mathrm{p}$ and a deletion of the subtelomeric region of chromosome $4 \mathrm{q}$ (Figure $3 \mathrm{a}$ and $\mathrm{b}$ ). The extension of unbalanced regions was measured by array-CGH, which showed that the duplicated $16 \mathrm{p} 13.3 \mathrm{p} 13.13$ region extended for about $12 \mathrm{Mb}$, from the probe A_14_P101770 to A_14_P122811 (12 088408 bp; Figure 4), whereas the deleted 4q35.2 band included about $4 \mathrm{Mb}$ of genomic DNA spanning from probe A_14_P123925 (187372 895 bp) to probe A_14_P129637 (191259499bp). 

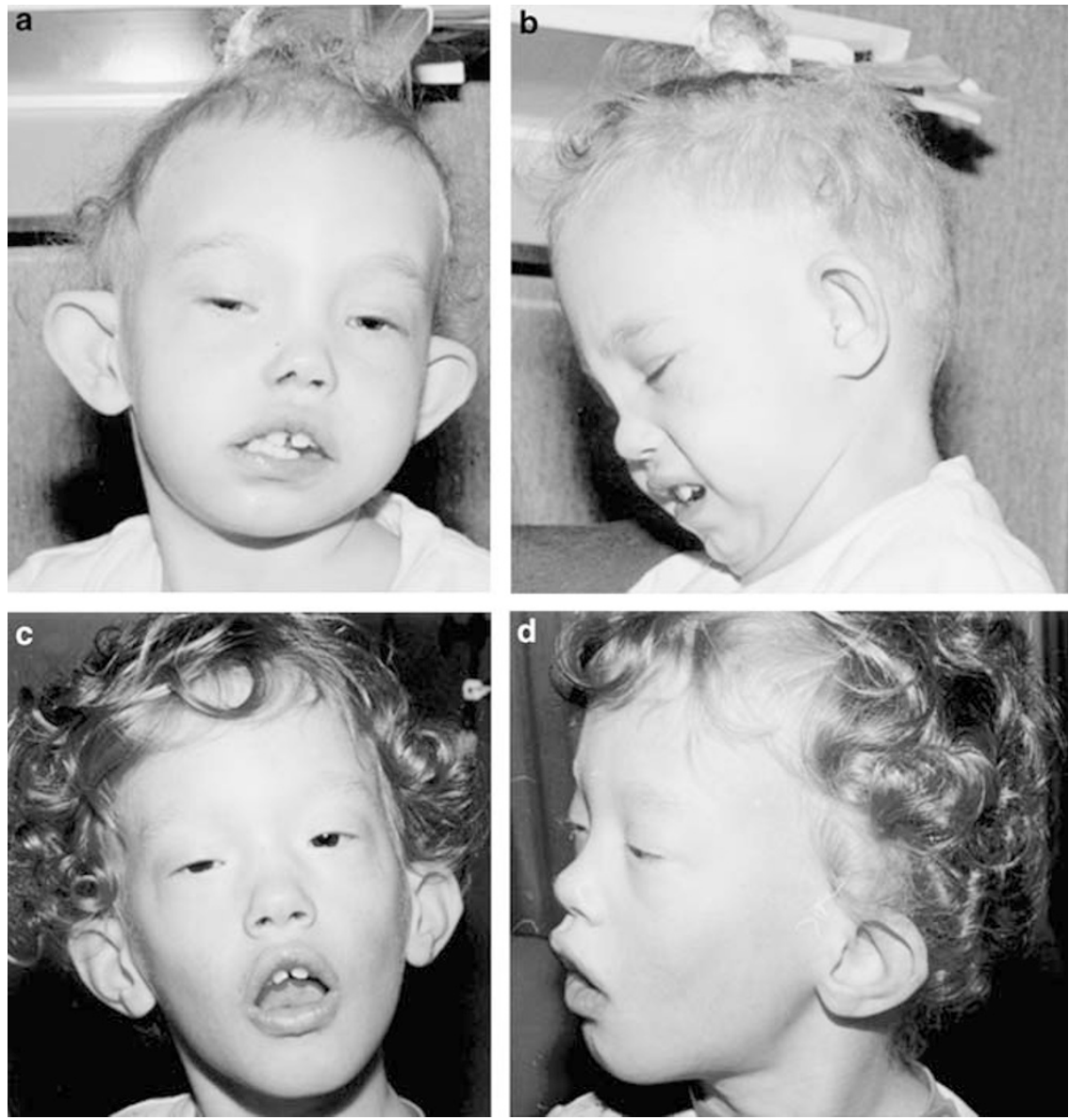

Figure 1 Frontal and lateral appearances of patient $1(\mathbf{a}, \mathbf{b})$ and patient $2(\mathbf{c}, \mathbf{d})$.

In patient 2, standard chromosome analysis was normal $(46, \mathrm{XX})$, whereas subtelomeric analysis disclosed a duplication of the subtelomeric region of $16 \mathrm{p}$ and a deletion of the subtelomeric region of $21 \mathrm{q}$ (Figure $3 \mathrm{c}$ and $\mathrm{d}$ ). This imbalance resulted from malsegregation of a balanced maternal translocation t(16pter;21qter). ArrayCGH showed that the duplicated region covered about $8.5 \mathrm{Mb}$ on $16 \mathrm{p} 13.3 \mathrm{p} 13.2$, from probe A_14_P101770 to probe A_14_P121597 (8857047 bp; Figure 4). Deletion of chromosome 21 spanned for about $300 \mathrm{~kb}$ in the subterminal region 21q22.3.

A duplication of the subtelomeric region of $16 p$ in the parents of patients 1 and 2 was excluded by array-CGH.

\section{Discussion}

The distinguishing clinical features of dup16p syndrome, limited to the terminal 16p13.1-p13.3 'critical' region,

Figure 2 Facial appearance of the patient with dup16p reported by Sommer et $a P^{9}$, showing striking similarity of the phenotype with patients 1 and 2 in this report (courtesy of Dr Sommer).

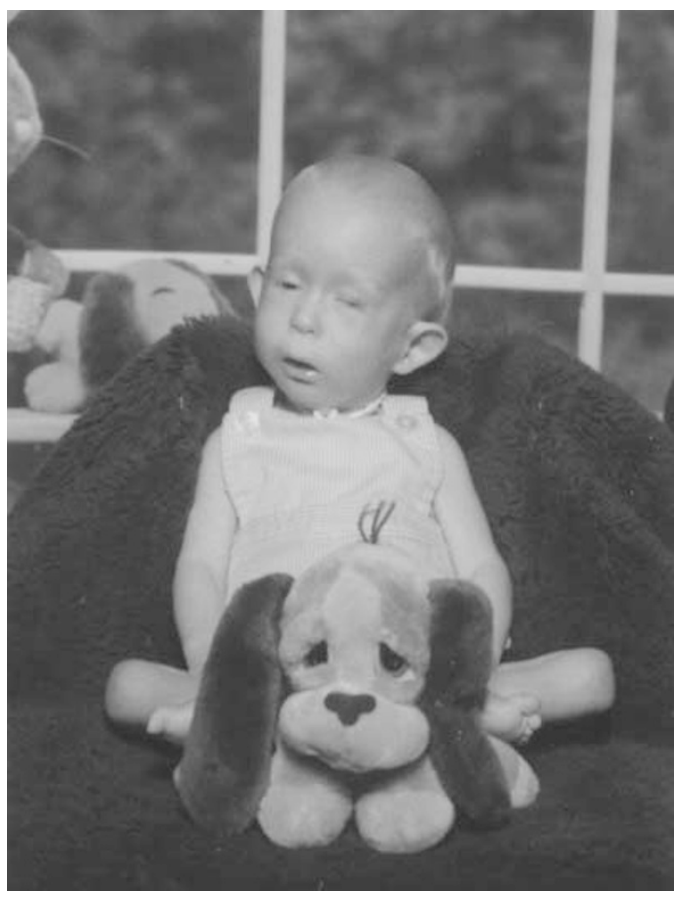

European Journal of Human Genetics 

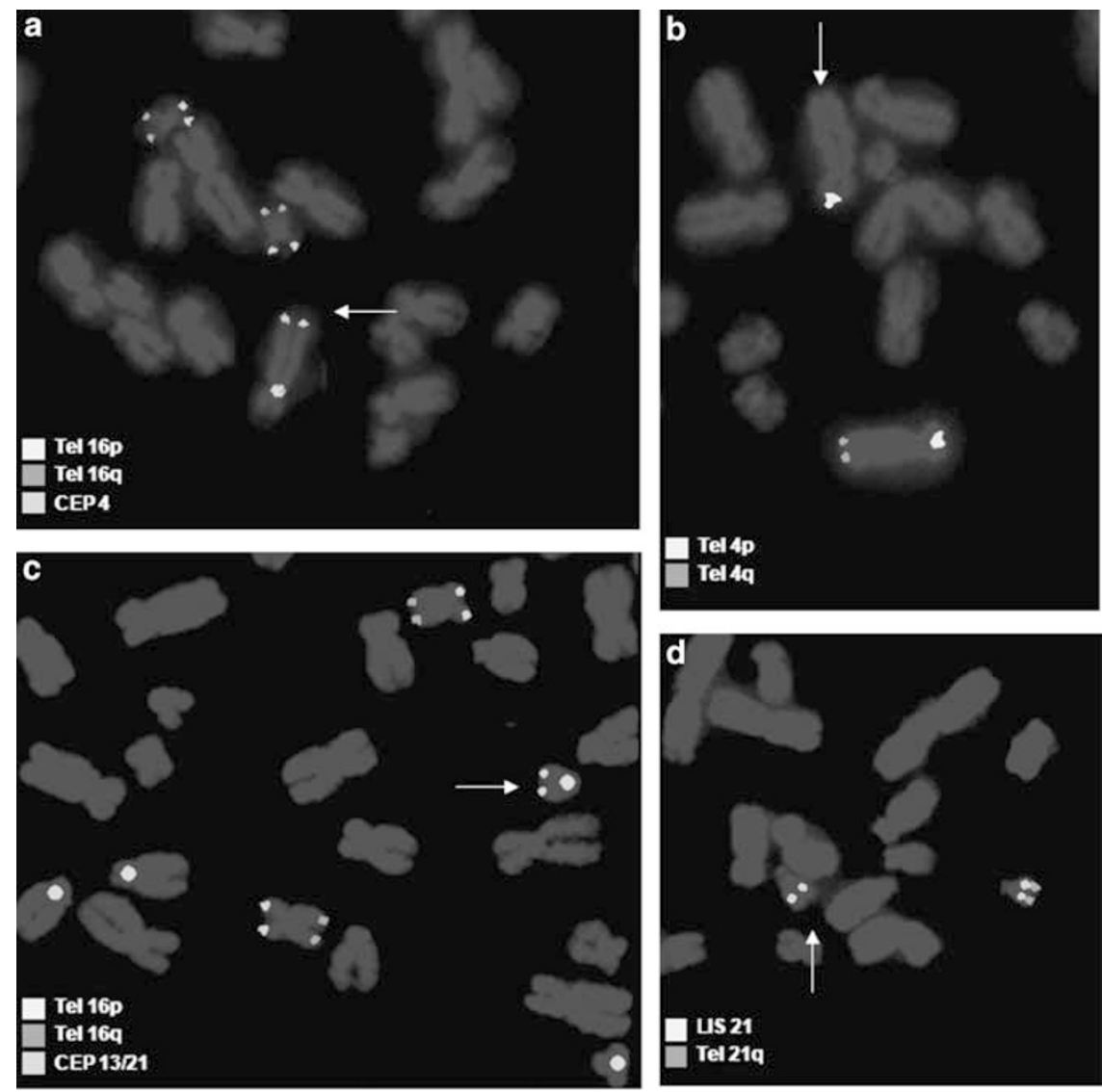

Figure 3 Patient 1: (a) Analysis of subtelomeric regions showing the duplication of the distal tip of 16p onto the subtelomeric region $4 q$, which was deleted (b). Patient 2: (c, d) The subtelomere $16 p$ probe discloses an additional signal (duplication) onto the distal $21 q$ region, which has only one signal (deletion). Arrows point to duplicated and deleted regions.

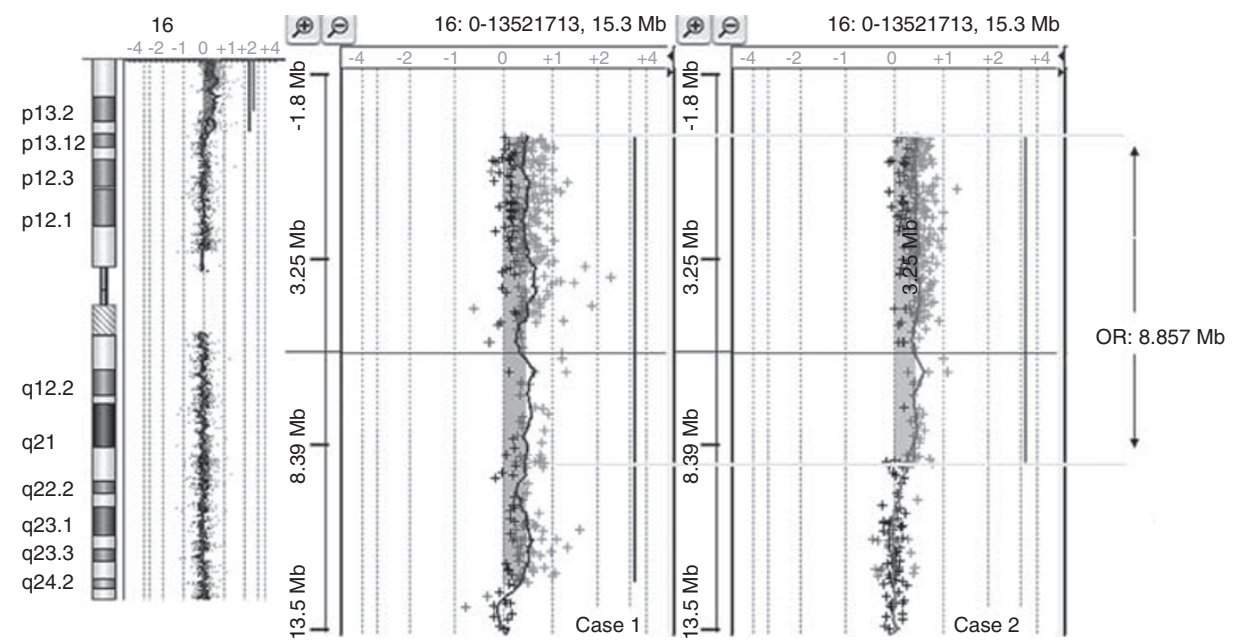

Figure 4 Oligonucleotide array-CGH analysis shows that duplication $16 \mathrm{p}$ in case 1 (blue vertical line) encompasses about $12 \mathrm{Mb}$, whereas in case 2 (green vertical line) is spanning for about $8.8 \mathrm{Mb}$, thus defining the overlapping duplicated region.

include specific facial anomalies, mental retardation, congenital cardiac and vascular defects, urinary malformations, and hypoplastic distal phalanges of hands (Table 1).
Craniofacial appearance is characterized by blond thin hairs, high forehead, sparse eyebrows, blepharophimosis with palpebral ptosis, short nose, open mouth with everted 
Table 1 Clinical features of patients with microduplication of the subtelomeric region of chromosome 16p (dup 16p)

\begin{tabular}{|c|c|c|c|c|c|c|c|c|c|c|c|c|}
\hline \multirow[t]{2}{*}{ Features } & \multicolumn{3}{|l|}{$\begin{array}{l}\text { Present } \\
\text { reports }\end{array}$} & \multicolumn{4}{|c|}{ Martin, 2002} & \multirow[t]{2}{*}{$\begin{array}{l}\text { Tschernigg, } \\
2002\end{array}$} & \multirow[t]{2}{*}{$\begin{array}{l}\text { de Ravel, } \\
2005\end{array}$} & \multirow[t]{2}{*}{$\begin{array}{l}\text { Sommer, } \\
2006\end{array}$} & \multirow[t]{2}{*}{$\begin{array}{l}\text { Ruiter, } \\
2007\end{array}$} & \multirow[t]{2}{*}{$\begin{array}{c}\text { Total } \\
\text { number, } \%\end{array}$} \\
\hline & Patient 1 & Patient 2 & 1 & 2 & 3 & 4 & 5 & & & & & \\
\hline Facial anomalies & + & + & + & + & + & + & + & + & + & + & + & $\begin{array}{l}11 / 11 \\
100 \%\end{array}$ \\
\hline Thin hair & + & + & + & $N$ & $N$ & + & + & + & + & + & $\mathrm{N}$ & $8 / 8,100 \%$ \\
\hline $\begin{array}{l}\text { Blepharophimosis/palpebral } \\
\text { ptosis }\end{array}$ & + & + & $\mathrm{N}$ & $\mathrm{N}$ & + & + & + & + & + & + & $\mathrm{N}$ & $8 / 8,100 \%$ \\
\hline Short nose & + & + & - & - & - & - & - & - & + & - & $\mathrm{N}$ & $3 / 10,30 \%$ \\
\hline Everted upper lip & + & + & $\mathrm{N}$ & $\mathrm{N}$ & $\mathrm{N}$ & $\mathrm{N}$ & $\mathrm{N}$ & - & + & + & $\mathrm{N}$ & $4 / 5,80 \%$ \\
\hline High arched palate & + & + & $\mathrm{N}$ & $\mathrm{N}$ & + & - & - & + & + & + & $\mathrm{N}$ & $6 / 8,75 \%$ \\
\hline Cleft lip/palate & - & - & - & + & + & + & + & + & + & - & + & $7 / 11,63 \%$ \\
\hline Micrognathia & + & + & + & + & $\mathrm{N}$ & - & - & - & + & + & $\mathrm{N}$ & $6 / 9,67 \%$ \\
\hline Cupped/dysmorphic ears & + & + & + & + & $\mathrm{N}$ & + & + & + & + & + & $\mathrm{N}$ & $9 / 9,100 \%$ \\
\hline \multicolumn{13}{|l|}{ Hands/feet anomalies } \\
\hline Hypoplastic digital phalanges & - & + & $\mathrm{N}$ & $\mathrm{N}$ & + & - & - & - & - & - & - & $2 / 9,22 \%$ \\
\hline $2-3$ toe syndactyly & - & - & $\mathrm{N}$ & + & $N$ & + & + & - & - & - & - & $3 / 9,33 \%$ \\
\hline Congenital heart defect & + & - & - & - & + & + & - & + & - & - & - & $4 / 11,36 \%$ \\
\hline Atrial septal defect & + & - & $\mathrm{N}$ & $\mathrm{N}$ & + & + & - & + & - & - & - & $4 / 9,44 \%$ \\
\hline Ventricular septal defect & - & - & $\mathrm{N}$ & $\mathrm{N}$ & - & - & - & + & - & - & - & $1 / 9,11 \%$ \\
\hline Aortic coarctation & - & - & $\mathrm{N}$ & $\mathrm{N}$ & - & - & - & + & - & - & - & $1 / 9,11 \%$ \\
\hline Patent ductus arteriosus & + & - & $\mathrm{N}$ & $N$ & - & - & - & - & - & - & - & $1 / 9,11 \%$ \\
\hline Vascular anomalies & + & - & + & - & - & - & + & + & - & - & - & $4 / 11,36 \%$ \\
\hline Pulmonary hypertension & + & - & - & - & - & - & - & + & - & - & - & $2 / 11,18 \%$ \\
\hline Portal vein cavernoma & + & - & - & - & - & - & - & - & - & - & - & $1 / 11,9 \%$ \\
\hline Vascular ring & - & - & $N$ & $\mathrm{~N}$ & - & - & + & - & - & - & - & $1 / 9,11 \%$ \\
\hline Aplasia cutis & - & - & + & $\mathrm{N}$ & $\mathrm{N}$ & - & - & - & - & - & - & $1 / 9,11 \%$ \\
\hline Urinary abnormalities & + & + & - & + & - & + & + & - & - & - & - & $5 / 11,45 \%$ \\
\hline $\begin{array}{l}\text { Vesicoureteral reflux/ } \\
\text { hydronephrosis }\end{array}$ & - & + & $\mathrm{N}$ & + & $N$ & + & + & - & - & - & - & $4 / 9,44 \%$ \\
\hline Renal hypoplasia & - & + & $\mathrm{N}$ & $\mathrm{N}$ & $\mathrm{N}$ & $\mathrm{N}$ & $\mathrm{N}$ & - & - & - & - & $1 / 6,17 \%$ \\
\hline Ectopic kidney & + & - & - & - & - & - & - & - & - & - & - & $1 / 11,9 \%$ \\
\hline Congenital hip dislocation & - & + & - & - & - & - & - & - & - & - & - & $1 / 11,9 \%$ \\
\hline Mental retardation & + & + & + & + & + & + & + & + & + & + & + & $\begin{array}{l}11 / 11 \\
100 \%\end{array}$ \\
\hline Seizures & - & - & + & - & + & - & - & + & + & + & - & $5 / 11,45 \%$ \\
\hline Corpus callosum hypoplasia & + & - & + & - & $\mathrm{N}$ & + & $\mathrm{N}$ & - & - & $\mathrm{N}$ & - & $3 / 8,38 \%$ \\
\hline Microcephaly & + & - & + & - & + & + & - & + & - & + & - & $6 / 11,55 \%$ \\
\hline Hearing loss & - & - & + & $\mathrm{N}$ & + & + & + & $\mathrm{N}$ & - & - & - & $4 / 9,44 \%$ \\
\hline $\begin{array}{l}\text { Approximate size of the } \\
\text { duplication }(\mathrm{Mb})\end{array}$ & 12 & 8.5 & 3.5 & 4.5 & 10 & 10 & 10 & $\mathrm{~N}$ & 4.5 & $\mathrm{~N}$ & $<0.2$ & \\
\hline
\end{tabular}

+ denotes present, - absent, and $\mathrm{N}$ not reported.

upper lip, high-arched palate, wide-spaced teeth, and cupped everted ears. Facial anomalies appeared strikingly similar in our two patients, and in those reported by de Ravel et al $^{10}$ and Sommer et al (Figure 2). ${ }^{9}$

Congenital heart defect, prevalently atrial septal defects, can be a feature of dup16p syndrome. Patients carrying large 16p duplications detected using standard techniques can manifest also tetralogy of Fallot or ventricular septal defect. ${ }^{5,13}$ A baseline cardiological evaluation is recommended at diagnosis, and periodic monitoring is warranted for the potential onset of pulmonary hypertension. Early onset of pulmonary vascular disease unresponsive to oxygen, as illustrated in our case 1 , has been reported previously in an infant with an inverted duplication of 16p11.2-p13.3. ${ }^{5}$ These two cases suggest that susceptibility to pulmonary vascular disease can be a feature of dup16p syndrome. Fixed pulmonary hypertension has been described also in an additional patient with a 46,XY,add(16)(p16.3).ish dup16(pterp13) karyotype. $^{7}$ However, in this case pulmonary hypertension could be related to congenital heart defect, consisting in a large perimembranous ventricular septal defect, an atrial septal defect, and hypoplastic aortic arch. Our case 1 had also a congenital portal cavernoma leading to portal hypertension, a feature not previously recognized in these patients. The portal cavernoma and the coexisting pulmonary 
feature of dup16p, suggesting that this subtelomeric region in some respect could be related to vascular anomalies.

spectrum of trisomy $16 \mathrm{p}$ syndrome, and argue for a possible association between this imbalance and vascular anomalies. Interestingly, vascular ring and manifestations of vascular disruption, as terminal hypoplasia of hands and aplasia cutis, have also been reported in association with dup16p (present patient 2). ${ }^{8}$

The phenotype of patients with dup16p is not specific for a specific Mendelian syndrome, although some aspects of facial appearance including blepharophimosis and hypoplastic teeth could suggest Ohdo syndrome. ${ }^{14}$

Previous observations have stated that chromosomal region 16 p13.1-p13.3 is 'critical' in determining clinical anomalies of the syndrome, and that the phenotypic severity could not be related to the size of the duplicated segment. Nevertheless, in patients with complete trisomy $16 \mathrm{p}$ it was not possible to identify a characteristic phenotype similar to that found in cases with duplication of the distal segment. ${ }^{15}$ Pre- and postnatal growth and mental retardation were more severe in patients with complete trisomy $16 \mathrm{p}$. A distinctive phenotype different to that identified in our patients has been recently described in a girl with duplication limited to the Rubinstein-Taybi region on $16 \mathrm{p} 13.3$, probably representing a single gene disorder. ${ }^{16}$ Clinical manifestations in that case included moderate mental retardation, tall stature, specific facial appearance, and hand/foot anomalies.

In our two patients, dup16p overlapped for about $9 \mathrm{Mb}$, from the $16 \mathrm{p}$ subtelomeric region to $16 \mathrm{p} 13.2$ band, and was associated with distal deletion of $4 \mathrm{q}$ in case 1 and distal deletion of $21 \mathrm{q}$ in case 2 . The clinical implications of the second imbalances should be also considered. However, the distinct facial dysmorphisms and vascular anomalies usually are not found in patients with these isolated cryptic deletions, suggesting that the distinguishing features of dup16p syndrome result from gene dosage of the distal $8.8 \mathrm{Mb}$ region duplicated in our two patients (Figure 4).

In conclusion, we have confirmed the existence of a clinically recognizable disorder in patients with dup $16 \mathrm{p}$, involving the terminal $16 \mathrm{p} 13.1-\mathrm{p} 13.3$ region. Mental retardation, facial anomalies, and terminal hypoplasia of fingers are clinical handles for suspecting this rare syndrome, which can be confirmed by molecular-cytogenetic testing. Susceptibility to pulmonary hypertension and other vascular anomalies, as occurring in one of the present patients and in other published cases, can be a

\section{Acknowledgements}

We thank Dr Annemarie Sommer from the Ohio State University and Children's Hospital, Columbus, Ohio, and the parents of the patient for providing us Figure 2.

\section{References}

1 Leonard C, Huret JL, Imbert MC, Lebouc Y, Selva J, Boulley AM: Trisomy $16 \mathrm{p}$ in a liveborn offspring due to maternal translocation $\mathrm{t}(16 ; 21)(\mathrm{q} 11 ; \mathrm{p} 11)$ and review of the literature. Am J Med Genet 1992; 43: 621-625.

2 O'Connor TA, Higgins RR: Trisomy $16 \mathrm{p}$ in a liveborn infant and review of trisomy 16p. Am J Med Genet 1992; 42: 316-319.

3 Schinzel A, Kotzot D, Brecevic L et al: Trisomy first, translocation second, umiparental disomy and partial trisomy third: a new mechanism for complex chromosomal aneuploidy. Eur J Hum Genet 1997; 5: 308-314.

4 Juan JLC, Cigudosa JC, Gomez AO, Almeida MTA, Miranda LG: De novo trisomy 16p. Am J Med Genet 1997; 68: 219-221. Pulmonary hypertension and trisomy 16. Pediatr Cardiol 1998; 19: 187-189.

6 Kokalj-Vokac N, Medica I, Zagorac A, Zagradisnik B, Erjavec A, Gregoric A: A case insertional translocation resulting in partial trisomy 16p. Ann Genet 2000; 43: 131-135.

7 Tschernigg M, Petek E, Leonhardtsberger A, Wagner K, Kroise PM: Terminal tandem duplication of $16 \mathrm{p}$ : a case with 'pure' partial trisomy (16)(pter $\rightarrow$ p13). Genet Couns 2002; 13: 303-307.

8 Martin CL, Waggoner DJ, Wong A et al: 'Molecular rulers' for calibrating phenotypic effects of telomere imbalance. J Med Genet 2002; 39: 734-740.

9 Sommer A, Pastore M, Wenger G: Trisomy 16p: a longitudinal profile and photo essay. Am J Med Genet 2006; 140A: 174-179.

10 De Ravel T, Aerssens P, Vermeesch JR, Fryns JP: Trisomy of chromosome $16 \mathrm{p} 13.3$ e to an unbalanced insertional translocation into chromosome 22q13. Eur J Med Genet 2005; 48: 355-359.

11 Ruiter EM, Koolen DA, Kleefstra $\mathrm{T}$ et al: Pure subtelomeric microduplications as a cause of mental retardation. Clin Genet 2007; 72: 362-368.

12 Bernardini L, Palka C, Ceccarini C et al: Complex rearrangement of chromosomes 7q21.13-q22.1 confirms the ectrodactylydeafness locus and suggests new candidate genes. Am J Med Genet A 2008; 146A: 238-244.

13 Leschot NJ, Denef JJ, Geraedts JPM et al: Five familial cases with a trisomy 16p syndrome due to translocation. Clin Genet 1979; 16: $205-214$.

14 Ohdo S, Madokoro H, Sonoda T, Hayakawa K: Mental retardation associated with congenital heart disease, blepharophimosis, blepharoptosis, and hypoplastic teeth. J Med Genet 1986; 23: 242-244.

15 Rochat MK, Riegel M, Schinzel AA: Long-term follow-up of a 26-year-old male with duplication of $16 \mathrm{p}$ : clinical report and review. Am J Med Genet 2007; 143A: 399-408.

16 Marangi G, Leuzzi V, Orteschi D et al: Duplication of the tive phenotype. Am J Med Genet 2008; 146A: 2313-2317.
5 Movahhedian HR, Kashani DS, Bull D, Jones KL, Rothman A: Rubinstein-Taybi region on 16 p13.3 is associated with a distin- 